\title{
Economic Analysis on the Tragedy of the Commons of River
}

\author{
Weikang Zhang, Weizhong Zeng (Corresponding author), Xinhong Fu, \& Jimin Pan \\ School of Economics \& Management, Sichuan Agricultural University \\ 211 Huimin Road, Wenjiang District, Chengdu 611130, China \\ Tel: 86-155-2073-5340Ｅ-mail: 84369788@qq.com \\ Hong Guo \\ Developmental Center of Sichuan Rural Science and Technology \\ 3 Chengke West Road, Chengdu 610041, China \\ Tel: 86-133-2096-8212Ｅ-mail:guohong424@126.com
}

Received: July 2, $2011 \quad$ Accepted: August 15, $2011 \quad$ doi:10.5539/jms.v1n1p124

This research is financed by Chinese Ministry of Education; the project is: Research on the ecological compensation system and corresponding strategies of Min River in Sichuan (09YJAZH061).

\begin{abstract}
The tragedy of the commons of river describes the plight of continuous exhaustion of the river resources. Its essence is because resources are excessive used. It takes the river pollution as an example in this paper, under the traditional hypothesis of classical economics, to analyze the reasons for the formation of tragedy of the commons of the rivers briefly, which is caused by repeated pollution actions among the inhabitants and the institution is important to solve it resultantly, in the view of game theory. Then, on the basis of New Institutional Economics (NIE), the discussion separately from microscopic, intermediate and macroscopic perspectives explores and answers what the institutions should be for tragedy of the commons of the rivers. Next is the case analysis of Jinhua River. It comes to the conclusions: the government could exploit planning mechanism and price mechanism generally, providing proper river property rights arrangement, to reduce various transaction costs and establish the river compensation system.
\end{abstract}

Keywords: The tragedy of the commons, The rivers, Game theory, New institutional economics (NIE), Transaction costs

\section{Introduction}

G. Hardin set out the following scenario in his paper named the tragedy of the commons in the assumption of rational persons in 1968 that: a herdsman increased a domestic animal additionally on a lawn would simultaneously bring both positive and negative effect, the former was bore completely by this herdsman, however the latter actually was undertook by all the herdsmen. Under the benefit obligation, each rational herdsman naturally fell into an unlimited mechanism of increasing domestic animals so that the lawn was unable to withstand the load to face the depletion situation, which was called the tragedy of the commons by Hardin visually (Hardin, 1968).

The tragedy of the commons points out what difficulty public resources or public goods are encountered in reality, and the "commons" explains the attribute of the public goods, the "tragedy" reveals the living condition of it. Notable features of public goods are non-exclusive and indivisible, the river, as an important natural resource, belongs to the category of the public goods; the biggest problem of rivers can be summarized as the tragedy of the commons of river.

River resources are now in the public property rights, such ambiguous property rights results in overspent of river resources, this will hinder the sustainable development of river resources and society undoubtedly. This paper takes river pollution as argument, on the basis of the assumption of game theory, to analyze briefly the reasons for the tragedy of the commons of river, from the microscopic, intermediate and macroscopic perspectives of the NIE, to investigate the countermeasures for the tragedy of the commons of river. Then, it 
explores the practical experiences and drawbacks on a case of Jinhua River to prove the above analysis; the final are some corresponding conclusions. These efforts may provide some theoretical and practical learning for the sustainable development of the rivers.

\section{Game Analysis of Reasons for the Tragedy of the Commons of River}

The tragedy of the commons can be divided into two types: the depletion of resources and the environmental damage, the former can be the result of the latter at last. In order to settle the plight of the tragedy of the commons reasonably to promote the sustainable development of environment, it is necessary to explain the reasons for its occurrence firstly. Some scholars in this area have studied and paid attention to in China. Yuan set up a mathematical model and economic graph to interpret the reasons for the former, and gives some suggestions (Yuan, 2007). Jiang found that the lag and misunderstanding of the multi-dimensional value theories provided by the rivers in Chinese history resulted in the river resources changed from public resources to the tragedy of the commons (Jiang, 2006). Ge believes the serious pollution in the process of China's economic growth is the mainly reason for the tragedy of the commons (Ge, 2005). In summary, these studies have discussed the reasons for the tragedy of the commons from different views, but these did not discuss the causes or countermeasures about the tragedy of the commons of river; this paper attempts to achieve this goal by economic analysis. Zhan took the sheep number of Pareto optimal, assuming it to be $\mathrm{K}$, as example to analyze the reasons and solving strategies for the tragedy of the commons with the method of related game (Zhan, 2003). His analysis treated K as the boundary to interpret the tragedy of the commons, for instance, to exploit whether the pollution is excessive or under the standardization of $\mathrm{K}$. But the key issue is $\mathrm{K}$ cannot be quantitatively accurate generally in fact. This paper is different from that even the game theory is also applied.

\subsection{Some Elementary Hypothesis}

(1) The players are rational; their strategies are to pollute (P) and not to pollute (NP). Moreover, they could observe these behaviours mutually;

(2) The river is a shared resource of all the players who are supposed to be a number of $Y$. The typical players A and B are selected to carry on the game analysis to keep the analysis as convenient and explicit as possible;

(3) Each player releasing a unit pollutant will receive the payoff of $a$. Namely, marginal benefit of pollution for everyone is $a$ (It is supposed that the river's total pollution capacity is limited and $T$ ). If only one chooses to pollute, the loss is undertook by all, thus the other one who doesn't pollute gets $-a / Y$. The benefit will be 0 (Note 1) if neither pollutes (it does not take the ecological benefit into account in short-term analysis);

(4) The both sides are aware of all the strategies and payoffs completely;

(5) The river itself has a certain self-purification capacity, which is considerably limited. The optimal amount of pollution is a number when marginal pollution is equal to marginal self-purification, set it as $Q$ (Note 2);

(6) The river originally was not polluted. The alternative game-analytic strategies begin after the players start to use the river resources.

\subsection{Game Analysis of the Short Term}

Table 1 expresses the payoffs matrix of the simultaneous-move game for both players, the situation should be firstly studied. If A chooses $\mathrm{P}$, the optimal choice of B is NP, because the payoff of NP is -a / $Y$, even though A chooses NP, P is his best choice as well, B's dominant strategy is P obviously. Similarly, regardless of whatever choice made by B, A's dominant strategy is $\mathrm{P}$. Nash equilibrium strategy of the stage simultaneous-move games is $(\mathrm{P}, \mathrm{P})$.

In reality, some players do not choose P initially due to morality or other reasons. However, they will observe, study or use the first mover advantage because of their own rationality to change their strategies when they find that is profitable. Thus, to construct a dynamic game model will be more realistic to interpret their actions. Then the entirely non-cooperative dynamic game model is constructed according to the previous assumptions.

Table 2 illustrates the dynamic game as mentioned above, which is a singleton game of perfect information. We can know the action set of $A$ is $S_{A}=(N, N P)$ from description. There are two strategies of each single node for player B and four pure strategies in all. They are as follows separately:

$$
\mathrm{S}_{\mathrm{B}}=\left\{\begin{array}{l}
\text { Regardless of whatever A picks, I will pick P; } \\
\text { If A picks P, I will pick P; if A picks NP, I will pick NP; } \\
\text { If A picks P, I will pick NP; if A picks NP, I will pick P; } \\
\text { Regardless of whatever A picks, I will pick NP; }
\end{array}\right.
$$


The Information sets of pure strategy corresponded to the order of the above respectively are: (P, P), (P, NP), (NP, $\mathrm{P}),(\mathrm{NP}, \mathrm{NP})$.

Figure 1 reveals almost all the information of the game (e.g. A can choose before B). Next, it can apply backward induction method to solve the perfect Nash equilibrium in accordance with the information from Figure 1 as follows: B's optimal strategy is (P, P) in the stage two, namely whatever A pick in stage one, B will choose $\mathrm{P}$ in that if A picks NP, B will obtain the payoff of $a-a / Y>0$, even if A picks $\mathrm{P}$, B will still get the payoff of $a-2 a / Y>0$, which is got much better of picking NP. Nonetheless, A will anticipate B's strategy described as above when he makes his mind, hence P is the optimal action of A. All in all, (P, P) is the perfect Nash equilibrium of this game.

The previous analysis illustrates the case of two players, given that the residents of river are numerous and possibly involved, their behaviours will be continuously carried on evidently, so studying on a repeated and limited times (Note 3) game should be more realistic. The repeated game gets the hypothesis as before. Imagine that the third player starts to enter the game. He, a newcomer, will treat all the actions of A and $\mathrm{B},(\mathrm{P}, \mathrm{P})$, as a whole sensitively, at the same time, he can anticipate his and the next newcomer's choices of NP will be incredible for each other, his optimal strategy is P resultantly. Similarly, the fourth entrant will select $\mathrm{P}$ in the nature of things. So, an analogy procedure happens afterwards, when $Y$ players are entirely involved in the game, all the newcomers will pick $\mathrm{P}$ that leads the final unique subgame perfect Nash equilibrium is $(\mathrm{P}, \mathrm{P})$. This means everyone's choice is $\mathrm{P}$ when the game repeats finite times. Even the river gets a certain self-purification capacity of $Q$ (whether it exists or can be known in advance or not), people's total pollution will soon exceed such an amount and their actions will keep continuous. Finally, the situation of making mistakes unrepentantly appears just like the description by Hardin. The river is plunged into an over-polluted position, which is impossible in sustainable development.

\subsection{Game Analysis of the Long Term}

The above analysis distinctly infers that when the game enters into the long-term stage, the situation may be more serious. Only does the way to change players' payoffs can change their strategies to achieve some new game equilibrium. There are two aspects to illustrate the above issues: firstly, when the amount of pollution tends to $T$ gradually, the negative ecological effects show clearly, income will be reduced even to the negative by degrees, at that time the players will change their strategies through the endogenous game rules. While the river will be contaminated too severely to recover by far, it is not wise to do so; secondly, changing of the payoffs through a series of constraint conditions will be more effective than the former approach. That is to say, the institution which is regarded as the carrier of constraint conditions should be paid more attention. As North said in his seminal book: Institutions are the rules of the game in a society or, more formally, are the humanly devised constraints that shape human interaction......In the jargon of the economist, institutions define and limit the set of choices of individuals (North, 1990). The essence of institution is to produce incentive effects, then, what work should the institutions do to protect river from tragedy?

\section{New Institutional Economic (NIE) Analysis of the River's Tragedy of Commons}

\subsection{Microscopic Analysis of NIE}

The assumptions of NIE are bounded rationality and incomplete information of human beings, which is opposite to that of Game Theory, yet, closer to the real world. Also in the 60s of last century, Coase described the tragedy of the commons too, taking the cattle as example, in his classic paper named the problem of social cost (Coase, 1960). He indicated the reason why people were engaged in such activities, from which they endlessly get more personal interest than social cost, was the ambiguous property rights resulted from the marginal personal income is greater than the marginal social cost dispersed into society and shouldered by other individuals. The firms appear to reduce the transaction costs of tradeoffs, which is a representative of the planning mechanism (Coase, 1937). It means the planning mechanism can substitute the price mechanism. Meanwhile, the latter can replace the former which can be attributed to the decline of transaction costs.

Therefore, the planning mechanism of government and the price mechanism of market should go hand in hand and replace with each other to reduce transaction costs in the process of river management. Moreover, the corporate boundary should be controlled to a point that the cost of planning mechanism must be equal to the cost of price mechanism when they complete the same tradeoffs (Coase, 1937). It means a power limit for government; it looks like a corporate, in the river management. In general, the government's power limit is born when the government administration and market tradeoffs have the same effect and each marginal cost is equal. In the strategies of the tragedy of the commons of river, the role of price mechanism has been underestimated, the invisible hand of river market does not play its full role, so it is the highly time that the government used 
price mechanism to replace part of planning mechanism.

The key to price mechanism is the goods can be dealt with each other under a definitely clear property rights. But the river, as a large carrier of natural resources, establishes a pure private property rights that will produce huge transaction costs or bring a tragedy of the anti-commons phenomenon (Heller, 1998) because of the underutilization of resources. In addition, the application of extreme common property rights will increase dramatically the rent dissipation of river resources; the situation will be more serious. Therefore, the possible property rights form exists between the pure private property rights and extreme common property rights (Cheung, 2000). That is to say the possible method is to implement some necessary regulations or limitations, then the institutions, involving a series of constraint conditions, should be set up to reduce the transaction cost brought by uncertainty and asymmetric information. What is more, the institution needs a trial and error, part of property rights, placed into the public domain (Bazel, 1997), will lead to lots of transaction costs from bargaining, so the rules should be clear enough to avoid unnecessary dissension, which would be best provided by the law. Not only is the main function of this institution to guarantee the river materials can own a clear property rights and transact freely in the market, but also establish the river management system in line with ethics and equity, such as ecological compensation system. Meanwhile, such project is so costly that only can be provided by the government.

\subsection{Intermediate Analysis of NIE}

All the players of river can be approximately regarded as an interest group whose common pursuit is to maximize their benefits from river resources, but they get into a dilemma of collective action at last described by the above game analysis. All the groups can be divided into two parts of compatible groups and exclusive groups (Olson, 1995). The stakeholders of the group are facing a minute cake situation, playing a zero-sum game, and are mutually exclusive. But this cake is depleted; therefore, individual rationality ultimately leads to unprofitable interest. The compatible group will be easier to achieve the common interest than the exclusive one generally; then, the corresponding institutions should be set to make the river interest groups transformed from exclusive group to compatible group so that the zero-sum game can become positive sum game. The key to do so is to change the direction of the utility function, and consequently the representative function of the interest will be the protection function rather than the pollution function.

Clearly, some selective incentive institutions can complete the transformation described above (Olson, 1995), namely, by implementing a system of clear incentive and penalty for members of interest group. For example, establish the river ecological compensation mechanism on relevant stakeholders, includes penalty for damage and encouragement for protection. Not only does the amount of punishment include the value of contaminative resources, but also a part of the incentive so that the return of pollution is a negative number. Not only does the amount of award include the protection cost, but also a part of incentive so that the protection gains a positive number. The purpose of this is to change the direction to achieve compatibility. However, there are so many stakeholders of the river interest groups, and defining the property rights, reducing the scale or members of the groups as well as decreasing the transaction cost for definition are all the prerequisites to implement compensation, so it is too difficult to define the compensation stakeholders.

\subsection{Macroscopic Analysis of NIE}

In considering the institutional change from the macroscopic horizon, in the short term, it is difficult to persuade the players to stop from utilizing the resources in terms of conscience or morality, besides, the cost is quite high. The public order and good of mankind exists as an informal institution, its formation is very difficult but has a far-reaching and lasting influence on behaviors of human being. When the formal institution works in the long run effectively, people will enjoy the long-run benefit and form an informal institution gradually and instinctively because of the institution restriction. As the river protection formed, non-polluting behaviour will become endogenous variable to form the self-protective behaviour; the tragedy of the commons can be finally resolved practically. This also further illustrates that more attention should be paid to the establishment of the informal institution to solve the tragedy of the commons, although the formation of tragedy is a short-term process, while it is a long process to get out of it.

\section{A Case Study on Jinhua River}

\subsection{Presentation of the Case}

Jinhua River is located in the central region of Zhejiang Province and flows through four counties in turn: Pan'an, Dongyang, Yiwu and Jinhua, which is about 200 kilometers and can be defined as a medium-sized river. In 2003, Pan'an's population was 2,062 million, but, Dongyang, Yiwu and Jinhua population are all three times more than 
that of Pan'an; per capita GDP of Pan'an was 8007yuan (RMB), whereas Yiwu, Dongyang had reached 17,973yuan and 27,783yuan separately. Pan'an situated in the upstream of the river had made a lot of work to control the pollution and protect the water resources, so the water quality had been greatly preserved and improved. In comparison, the highly developed industrial economy of Yiwu and Dongyang result in the further deterioration of water quality in Jinhua River showed by Table 3 (Zheng, 2010), which indicates a serious problem that the upstream was protecting, meanwhile, the downstream was polluting.

In recent years, the population of Yiwu, with another name of "the Chinese Commodity City", has reached to nearly 35 million; the water scarcity and industrial pollution severely restrict the continued development of the economy, the sustainable development has faced a serious threat. With the industrial and social development, the river's tragedy of the commons will become more serious. It is unable to meet the basic needs of industrial and domestic despite the establishment of Badu Reservoir in Yiwu. However, the water resources are very rich and the water quality is much better in Dongyang, the per capita water resources of Dongyang is almost $90 \%$ more than Yiwu. Two large reservoirs, Hengjin and Nanjiang reservoirs are in Dongyang. More than 3,000 tons of water are lost except meeting their own needs every year. Especially 165 million cubic meters of water are not being used in Hengjin Reservoir, in addition to the demand of irrigation and water supply for Dongyang (Zheng, 2010).

There are three solutions for Yiwu facing the situation of water pollution and shortage: firstly, expanse the existing reservoirs; secondly, build up some new reservoirs; thirdly, invest to transfer water from other places. Yet, due to industrial pollution and the terrain in Yiwu, it is not suitable for the construction of the reservoir, thus, the third option has become the only choice.

After five years of negotiations and preparation, in the November 24, 2000, an agreement on the transfer of water rights was signed between Dongyang government and Yiwu government. Provisions of the agreement are as follows:

Firstly, the Yiwu municipal government pays a one-time payment of 200 million yuan to buy 49,999 million cubic meters of water rights of Hengjin Reservoir per year, and the Dongyang government ensure the water quality conform the national water class of I , which is the best water rank in China;

Secondly, after the transfer of water rights, the original ownership of the reservoir is not changed, the Dongyang government is still responsible for the reservoir's engineering and maintenance. Yiwu government pay an integrated management fee of 0.1yuan, including water charges, for per cubic meter according to the annual actual water supply;

Thirdly, the pipeline from Hengin reservoir to Yiwu is designed and invested by Yiwu, Jin from the horizontal water project, City planning and design and by the investment and construction, the relevant policies and pipeline construction within Dongyang is responsible by Dongyang itself, but the cost is borne by the Yiwu.

After more than three years of intense construction, in the January 6, 2005, with the success of the project between Yiwu and Dongyang, it also declared the success of Chinese first water rights trading officially, which had attracted a lot of attention.

Yiwu and Dongyang has achieved some economic and social benefits since the successful launch of the first water rights trading in China (Qin, 2010). Many scholars take it as a typical case to analyze the innovation and experience of the water rights trading in Chinese water resources management (Wang \& $\mathrm{Hu}, 2001$; Wang \& Han, 2003; Shen, 2005; Shen \& Zhu, 2006; An \& Yin, 2007; Zheng \& Xu, 2007; Zhao \& Hu, 2007; Zhang, 2010). Overall, these findings were all concluded: this was a great innovation in China's water resource management, which had broke the difficult situation of river administration by government and would be of great significance in the history of water management in China. With the success of this practice, water trading have started in other places of China gradually, such as: emission rights trading in Shanghai and Jiaxing (Shen, 2004); Zhangye, in Gansu province, used the water rights of irrigation to trade to make a water-saving attempt (An \& Yin, 2007).

From a view of the project efficiency, Dongyang started to save and protect the water resources after acquirement of the funds. Moreover, the per cubic meter water could get a benefit of 4yuan but the cost of it was less than 1yuan when the water rights was transferred to Yiwu. Although Yiwu paid 4yuan for the cost of per cubic meter of water, but if they chose to establish the new reservoir, it would be 6yuan of per cubic meter. The deal reached the cost-effective win-win situation at last, improving the social welfare level of Dongyang and Yiwu. Especially Yiwu solved the difficulty on the water bottleneck, or it can be said the tragedy of the commons dilemma, through water rights trading at little cost and laid a solid foundation for the construction of the International Trade City. The 200 million yuan and the investment funds from pipeline project obtained by water 
trading for Dongyang energized the development of economy, in addition to helping to promote the water and environmental quality around Hengjin Reservoir and achieve the environmental and economic win-win situation. In general, the water rights trading between both sides is an effective way to make the river kept sustainable, and the tragedy of the commons of Jinhua River has been alleviated to some extent. But it also brought some negative effects, for example, the interests of some farmers who were belonged to the Hengjin irrigation damaged (Zhao, 2007).

\subsection{Discussions of the Case}

The following conclusions can be drawn, through the NIE analysis and the case above:

Firstly, market mechanism is an effective means to allocate water resources. It can definitely improve the efficiency of resources' allocation. This is a case of the synthesis of commons resolutions and implications for marketing engagement and the stakeholder negotiation and compliance model for commons management (Shultz \& Holbrook). Furthermore, the success between both sides is a typical case that the market mechanism can replace government planning mechanism to a more effective resources' allocation. This is a major institutional innovation and the inevitable result of induced institutional change in China. It has actually reduced the tragedy of the commons of Jinhua River. But the government as the main dealer, which is single and largely restricted in the market, should give more space to non-governmental dealers so that water rights trading can be more flexible to play the role of price mechanism.

Secondly, clear water property rights are the primary condition for water rights trading. In theory, water rights belong to the nation. Therefore, the ownership, the management rights and the use rights are serious separated result in great difficulties for property rights trading. Water rights trading is the redistribution of ownership, which must be clear defined. Obviously, from the point of overall Jinhua River, the water rights is not very clear defined that Pan'an, in the upstream of the river, is excluded. Nonetheless, it is the source of water and has the qualifications to profit. In addition, in order to protect water resources, Pan'an lost the economic development opportunities, but it did not receive appropriate compensation, offering the incentive to make them continuing to protect water resources. Besides, sound and clear feedback channels of ecological services are not established all over the river displayed by Figure 2, which will not be helpful to the transmission of information and decrease transaction costs.

Thirdly, both governments did not establish adequate mechanisms for supervision and management, and there is no strong legal system to provide the definition of water rights and transaction process. In addition, the contract signed is not perfect. Indicatively, it did not provide some approaches to the possible disputes after the water rights trading. All these may increase the implementation costs and afterward transaction costs. The transaction costs is the key variable for China's water rights trading (Shen, 2004), whether the trade occurs or not, the frequency and the net profit of the water rights trading all depend on their transaction costs (Colby, 1993).

\section{Conclusions}

From a view of rational persons, the reason for the tragedy of the commons of river is the repeated pollution game among players in the short term, while the implementation of institution is very important for solving these problems in the long run. Then, this paper discusses what institutions should work for the tragedy of the commons of river from microscopic, intermediate and macroscopic views of the NIE respectively and a case of water rights trading of Jinhua River, which is the first practical experience in China. It can draw the following conclusions through the above analysis:

Firstly, the general idea to solve the tragedy of the commons of river to achieve rivers' sustainable development is to use a combination of government's planning mechanism and the market's price mechanism to optimize the allocation efficiency of river resources, and to minimize transaction costs in the process of implementation of various institutions.

Secondly, the existing government-led river management ought to leave some space to the market to carry out price mechanism and provide appropriate institutional arrangement and property rights arrangement of river management actively, as well as offer the platform for information exchange to support market tradeoffs. The institution should be the strongest formal style such as the law, otherwise the constraint force of institution will be influenced. The river management organization of government could control the scale, such as reducing the links of management and flow of information, to decrease the proportion of organization or operation costs in total transaction costs. It is necessary to establish the monitoring mechanism to control corruption, free riding and opportunistic behaviour that may have a great impact on the cost which is most important to resolve tragedy of the commons of the rivers in the whole process. 
Thirdly, reasonable arrangement of river property rights is the most important aspect to settle the tragedy of the commons of river. While the difficulty and transaction costs would rise with the increasing of the property rights objects, at the same way it will bring further exclusiveness of the interest groups. Given the wide range of river, the government should reduce the number of property rights stockholders. For example, local government can set up some special organizations on river property rights trading, which may be some non-governmental organizations, to represent local residents in order to play down the stockholders. Moreover, such organizations are supposed to work as the enterprises do in the market, namely, not only do they exercise the management function, but also sign a contract with other river organizations as a dealer. Furthermore, the rules and contents of contract will affect the later transaction cost largely; the cost and benefits brought by tradeoffs will be reapportioned and redistributed in the interest groups.

Fourthly, the compensation system is an effective way to balance the interest, which will change the rules of endogenous game by non-market methods and form the strong restriction force to protect river. The previous establishment of property rights, however, will provide compensation system clear objects and subjects to reduce the cost of compensation to improve the compensation benefits.

Lastly, although the establishment of some formal institutions are of great importance, but the publicity and education of public awareness would make the institutions flexible so that the hard constraints of formal institution and the soft constraints of informal institution can play a role jointly to improve efficiency.

\section{Acknowledgements}

We are grateful for the comments from anonymous reviewers, whatever the internal or the external, especially for the helpful revision advices of the latter, who promotes the manuscript greatly.

\section{References}

An Xindai, Yin Huijuan (2007). Current situation of water right trading home and abroad and feature of water right transfer in Yellow River. China Water Resources, 2007, (19), pp.35-37.

Bazel, Y. (1997). Economic Analysis of Property Rights. Shanghai: Shanghai Gezhi Press.

Bonnie G. Colby, Kristine Crandall, and David B. Bush (1993). Water Right Transactions: Market Values and Price Dispersion. Water Resources Research, 1993.29(6).

Cheung, S. N. (2000). Economic Explanation. Beijing: The Commercial Press.

Clifford J. Shultz, Morris B. Holbrook (1999). Marketing and the Tragedy of the Commons: A Synthesis, Commentary, and Analysis for Action. Journal of Public Policy \& Marketing, Fall 1999; vol. 18(2); 218-229.

Coase, R. H. (1937). The nature of the firm, Economica, New Series, Vol. 4, No. 16. (Nov., 1937), pp. 386-405. doi:10.1111/j.1468-0335.1937.tb00002.x, http://dx.doi.org/10.1111/j.1468-0335.1937.tb00002.x

Coase, R. H. (1960). The problem of social cost. Journal of Law and Economics, Vol. 3 (Oct., 1960), pp. 1-44. doi:10.1086/466560, http://dx.doi.org/10.1086/466560

Ge Zhongquan, Xie Wei, Zhang Bin (2005). The causes of the "tragedy of the commons" in the process of economic growth in China. Ecological Economy, 2005, (1) 4, pp.43-45.

Hardin, G. (1968). The Tragedy of the Commons. Science, 162, 1243-1248. doi:10.1126/science.162.3859.1243, http://dx.doi.org/10.1126/science.162.3859.1243

Heller, M. (1998). The Tragedy of the Anti-Commons: Property rights in the Transition from Marx to Market. Harvard Law Review, No. 3(January).

Jiang Tianwen, Fan Zhihong (2006). The internal mechanism of rivers changed from the public resources to the tragedy of the commons. Resources and Environment of Yangtze River, 2006, 15 (3), pp.315-319.

North, D. C. (1990). Institutions, Institutional Change and Economic Performance. Cambridge: Cambridge University Press.

Olson, M. (1995). The Logic of Collective Action. Shanghai: Shanghai Renmin Press.

Qin Qiongxia (2010). Benefit analysis on water rights trading in Zhejiang-Taking Dongyang and Yiwu for example. Modern business, 2010, (12).

Shen Dajun, Zhu Yonghua, Yu Jianjun (2006). Development and practice of water rights system in Zhejiang. China Water Resources, 2006, (21), pp.3-5.

Shen Manhong (2005). Water rights trading and the Government Innovation-Taking water rights trading of 
Dongyang and Yiwu for example. World of Management, 2005, (6), pp.45-46.

Wang Xiao, Han Baoping, Gu Qiang (2003). Seven basic systems to protect the establishment of China's water rights trading. Development Study of Water Resources, 2003, 3 (5), pp.22-24.

Wang Yahua, Hu Angang (2001). A major innovation on water rights system-using the theory of institutional change to investigate water rights trading of Dongyang and Yiwu. Development Study of Water Resources, 2001, 1 (1) 4, pp.5-8.

Yuan Qingming (2007). Research on reasons and countermeasures of resource-exhausted tragedy of the commons, Journal of Zhongnan University of Economics and Law, 2007(5), pp.9-13.

Zhan Zhiwei (2003). Game Analysis of the Tragedy of The Commons and its Treatment. Financial Theory and Practice, 2003, 24 (5), pp.49-52.

Zhang Weiying (2004). Game Theory and Information Economics. Shanghai: Shanghai Gezhi Press, (Chapter 2).

Zhang Yongliang (2010). The latest development and enlightenment of water trading between Dongyang and Yiwu. Theorists, 2010, (11), pp.81-83.

Zhao Liange, Hu Congyu (2007). The analysis of the economic impact of water rights trading in Dongyang-Yiwu,Zhejiang. Issues in Agricultural Economy, 2007, 28 (4), pp.47-53.

Zheng Haixia, Zhang Lubiao, Feng ZhiMing (2010). Ecological compensation mechanism and policy recommendations in Jinhua River. Resources Science, 2006, 28 (5), pp.30-35.

Zheng Haixia (2010). Research on Mechanism and Policy of the Ecological Services Compensation of Chinese Rivers. Beijing: Chinese Economy Press, pp.87-130.

Zheng Hantong, Xu Changxin (2007). Definition of water right assets in water right trading and its management scope. China Water Resources, 2007, (12), pp.38-40.

\section{Notes}

Note 1 . We don't consider short-term ecological benefits, in fact, it is difficult to quantify ecological benefits. The choice of rational players is based on explicit values (e.g. pollution's benefit).

Note 2. The small self-purification ability results in a very small $Q$, many analysts assume that players know $Q$, yet actually it is difficult to accurately quantify $Q$.

Note 3. Possible reasons are: 1, the river resources are limited, so is the pollution capacity, which is assumed to be $\mathrm{T}$ in this article; 2 , the players are quantitatively finite and the number is $Y ; 3$, some players will end the action because of some majeure factors, such as death.

Table 1. Payoff matrix of the simultaneous-move game

A

\begin{tabular}{|c|c|c|}
\hline & $\mathrm{N}$ & $\mathrm{NP}$ \\
\hline $\mathrm{N}$ & $(a-2 a / Y, a-2 a / Y)$ & $(a-a / Y,-a / Y)$ \\
\hline $\mathrm{NP}$ & $(-a / Y, a-a / Y)$ & $(0,0)$ \\
\hline
\end{tabular}

Table 2. Strategic expression of the dynamic game

A

\begin{tabular}{|c|c|c|c|c|}
\hline & $(\mathrm{N}, \mathrm{N})$ & $(\mathrm{N}, \mathrm{NP})$ & $(\mathrm{NP}, \mathrm{N})$ & $(\mathrm{NP}, \mathrm{NP})$ \\
\hline $\mathrm{N}$ & $(a-2 a / Y, a-2 a / Y)$ & $(a-2 a / Y, a-2 a / Y)$ & $(a-a / Y,-a / Y)$ & $(a-a / Y,-a / Y)$ \\
\hline $\mathrm{NP}$ & $(-a / Y, a-a / Y)$ & $(0,0)$ & $(-a / Y, a-a / Y)$ & $(0,0)$ \\
\hline
\end{tabular}


Table 3. Main pollutants density control in Jinhua River

\begin{tabular}{|c|c|c|c|c|c|c|}
\hline Counties & Water & $\begin{array}{c}\text { PH } \\
\text { Index }\end{array}$ & $\begin{array}{c}\text { Permanganate } \\
\text { Index }\end{array}$ & $\begin{array}{l}\text { Ammonia } \\
\text { \& Nitrogen }\end{array}$ & Fluoride & COD \\
\hline \multirow{2}{*}{ Pan'an } & Enter & 3 & 3 & 3 & 3 & 3 \\
\cline { 2 - 8 } & Leave & 3 & 2 & 5 & 3 & 2 \\
\hline \multirow{2}{*}{ Dongyang } & Enter & 3 & 2 & 5 & 3 & 2 \\
\cline { 2 - 8 } & Leave & 3 & 5 & $>5$ & 5 & $>5$ \\
\hline \multirow{2}{*}{ Yiwu } & Enter & 3 & 5 & $>5$ & 5 & 5 \\
\cline { 2 - 8 } & Leave & 3 & 5 & $>5$ & $>5$ & 4 \\
\hline \multirow{2}{*}{ Jinhua } & Enter & 3 & 4 & $>5$ & $>5$ & 4 \\
\cline { 2 - 8 } & Leave & 3 & 3 & $>5$ & 5 & 5 \\
\hline
\end{tabular}

(1) $(a-2 a / Y, a-2 a / Y)$

(2) $(a-a / Y,-a / Y)$

(3) $(-a / Y, a-a / Y)$

(4) $(0,0)$

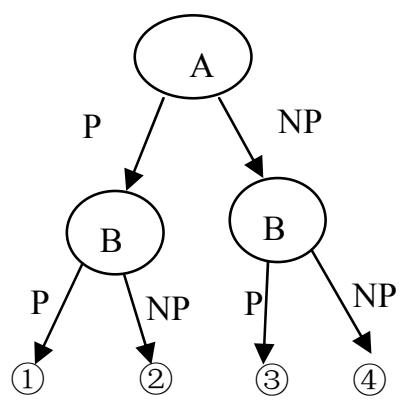

Figure 1. Extensive form representation of the dynamic game (Game Tree)

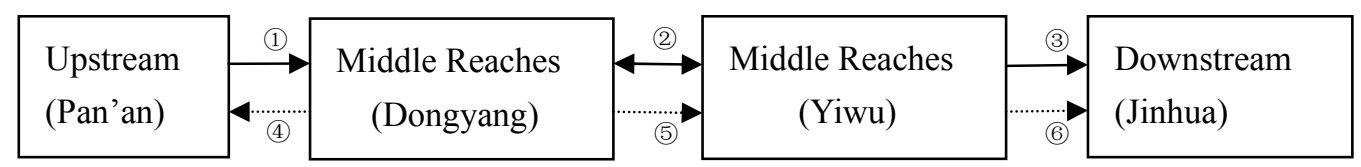

Notes: (1)Ecosystem services of water; (2)Water rights trading; (3)No ecosystem services of water; (4)Compensation; (5)Punishment for compensation; (6)Punishment for compensation. The dashed line expresses the behaviours should happen but not in fact, the solid line represents the behaviours have occurred actually. This figure is a research results from Zheng (Zheng, 2010), however, with some changes.

Figure 2. Channels of information on ecosystem services of Jinhua River 